\title{
The effect of the interlayer on the ballistic performance of ceramic/composite armors: Experimental and numerical study
}

\author{
A. Tasdemirci*, G. Tunusoglu, M. Güden \\ Dynamic Testing and Modeling Laboratory and Department of Mechanical Engineering, Izmir Institute of Technology, Gulbahce, 35430 Urla, Izmir, Turkey
}

\section{A R T I C L E I N F O}

\section{Article history:}

Received 1 November 2011

Received in revised form

16 December 2011

Accepted 19 December 2011

Available online 24 December 2011

\section{Keywords:}

Armor

Interlayer

Ballistic performance

LS-DYNA

Stress wave

\begin{abstract}
A B S T R A C T
The effect of rubber, Teflon and aluminum foam interlayer material on the ballistic performance of composite armor was investigated both experimentally and numerically. Although, rubber interlayer did not cause any significant delay in the initial stress build-up in the composite layer, Teflon and aluminum foam interlayer caused a significant delay and reduction in the magnitude of the stress transmitted to the composite backing plate. Damage in the ceramic layer was found to be highly localized around the projectile impact zone for the configuration without interlayer and rubber interlayer while aluminum foam and Teflon interlayer spread the damage zone in the radial direction. Relatively large pieces of the ceramic around the impact axis in the rubber interlayer configuration were observed while the ceramic layer was efficiently fragmented in aluminum foam and Teflon interlayer configuration.
\end{abstract}

(c) 2011 Elsevier Ltd. All rights reserved.

\section{Introduction}

Armor systems have been conventionally monolithic, typically composing of a high strength steel plate [1-4]. However, there is an increasing demand for the materials and multilayer material systems providing maximum ballistic protection at a minimum weight. Over the years, ceramics and polymer matrix composites have been increasingly incorporated into armor protection systems [5-13]. The composite armor, which is also known as multilayered armor system, is composed of a hard strike face made of ceramic tiles and a fiber reinforced composite backing plate. The main function of the front ceramic layer is to mitigate the local pressure imposed to the backing composite plate, by deforming and eroding the projectile. The composite backing plate absorbs part of the kinetic energy of the projectile. Metallic plates have also been investigated for the backing plate in multilayered armor systems [14-19].

When a projectile hits the ceramic layer at a relatively high velocity, a compressive stress wave is generated, propagating from the projectile hit/impact zone in the impact direction. Once this compressive wave reaches the back face of the ceramic layer, it is partially reflected back as tensile wave, causing the damage of the

\footnotetext{
* Corresponding author. Tel.: +90 2327506780; fax: +90 2327506701.

E-mail address: alpertasdemirci@iyte.edu.tr (A. Tasdemirci).
}

ceramic layer. Several studies have investigated the stress wave propagation in the composite armor both analytically and numerically [20-23]. The acoustic impedance mismatch between the ceramic and composite layer is known to play a key role in the ballistic performance of the armor system. In addition, the insertion of an interlayer between these two layers significantly alters the wave propagation characteristics and consequently the ballistic performance of the armor system. The effects of rubber interlayer and through-thickness wave propagation in an integrated composite armor system were previously studied [24,25]. It was reported that the rubber interlayer ensured a good resilient bond between the ceramic and composite and also enhanced the multihit capability of the armor system. The composite armor with an aluminum foam interlayer was shown to produce more extensive ceramic fragmentation and less volumetric delamination of the composite plate [26]. The effect of adhesive interlayer thickness on the ballistic efficiency of alumina/aluminum armor system was investigated both numerically and experimentally $[16,27,28]$. It was shown that the thicker layer of adhesive resulted in a wider plastic deformation area of the metallic backing plate and earlier shattering of the ceramic layer. The effects of wave speed, layer geometry and the mechanical properties of the layers on the load distribution between the layers were also investigated numerically $[29,30]$. It was reported that a single, thick, high strength and high wave speed layer for a fixed layer thickness provided the best lateral load spreading. 

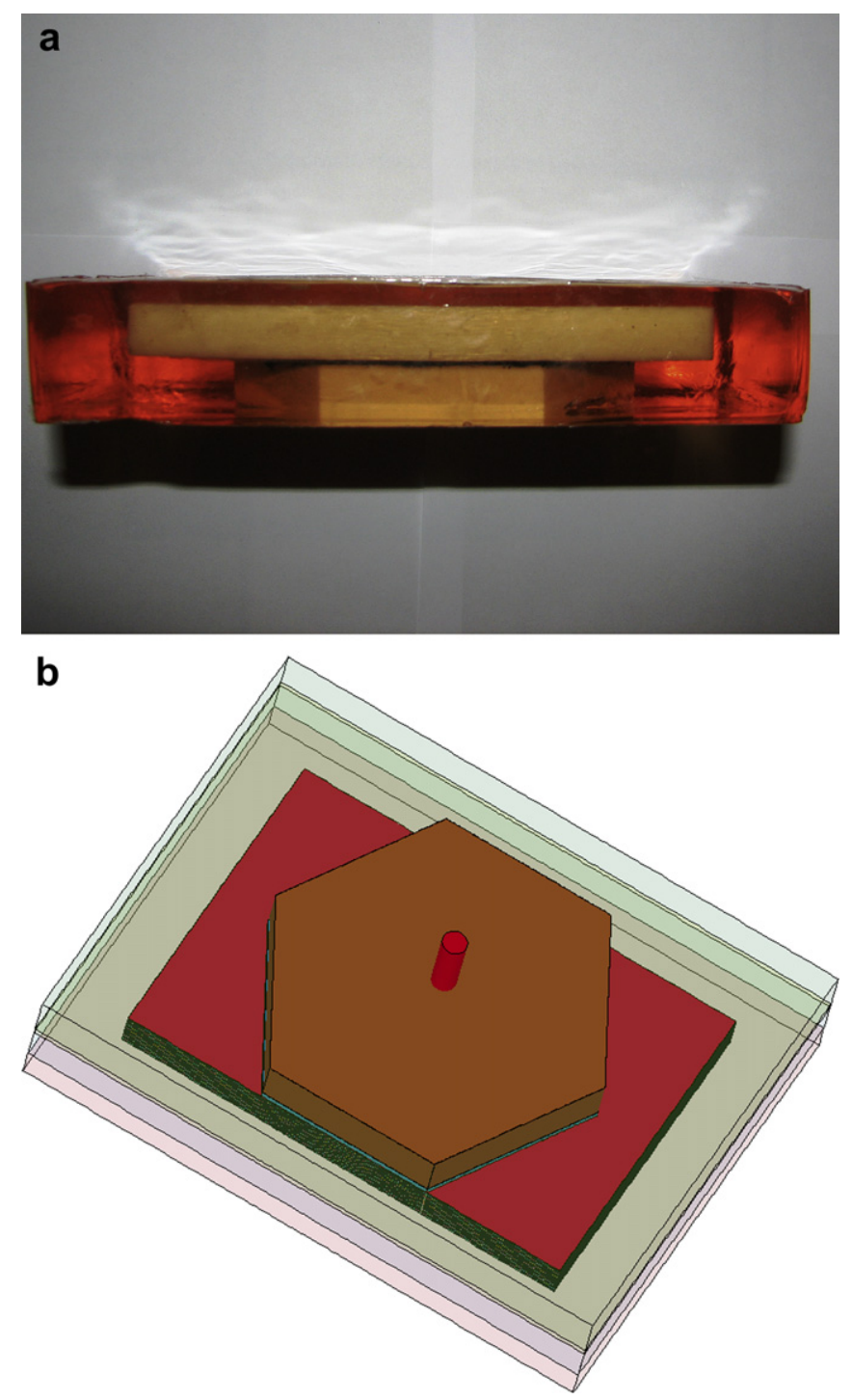

Fig. 1. (a) mounted ceramic/composite armor target and (b) finite element model of the projectile and target.

As the multilayered armor systems are becoming increasingly complex, the analysis of the wave propagation between the layers requires both modeling and experimental efforts. Previous studies have provided the first precise theoretical and experimental insights into the details of the stress wave propagation in these materials [31-33]. The Split Hopkinson Pressure Bar (SHPB) was used as a probe for generating entry and exit of the stress waves of known characteristics. These known, measured, entry and exit waves were then reproduced in a finite element model of the multilayer material. It was confirmed that when the model data matched the output data from the bars, the model was accurately describing the stress-state within the multilayer material including single, double and triple layered materials. These studies were mainly focused on the simulations the initial few microseconds;

Table 1

Johnson-Cook material model parameters for hard steel core [34].

\begin{tabular}{llllll}
\hline$\rho\left(\mathrm{g} / \mathrm{cm}^{3}\right)$ & $G(\mathrm{GPa})$ & $A(\mathrm{MPa})$ & $B(\mathrm{MPa})$ & $n$ & $m$ \\
\hline 7.83 & 81.8 & 1000 & 510 & 0.26 & 1.03 \\
$T_{\mathrm{m}}(\mathrm{K})$ & $T_{\mathrm{r}}(\mathrm{K})$ & $C$ & $C_{\mathrm{p}}(\mathrm{J} \mathrm{kg} \mathrm{K})$ & $\varepsilon_{\mathrm{f}}$ & $\varepsilon_{0}(\mathrm{~s})$ \\
1793 & 298 & 0.014 & 477 & 0.8 & 1.0 \\
\hline
\end{tabular}

Table 2

Johnson-Holmquist material model parameters for ceramic layer [38].

\begin{tabular}{lll}
\hline Parameter & Description & Value \\
\hline$\rho_{0}$ & Density & $3.89 \mathrm{~g} / \mathrm{cm}^{3}$ \\
$G$ & Shear modulus & $123 \mathrm{GPa}$ \\
HEL & Hugoniot elastic limit & $8.00 \mathrm{GPa}$ \\
$A$ & Intact strength constant & 0.949 \\
$N$ & Intact strength constant & 0.2 \\
$C$ & Strain rate constant & 0.007 \\
$B$ & Fracture strength constant & 0.1 \\
$M$ & Fracture strength constant & 0.2 \\
SFMAX & Max strength of failed mat'l/HEL stress & 1.0 \\
$T$ & Tensile strength & $0.262 \mathrm{GPa}$ \\
K1 & Pressure (EOS) constant & $186 \mathrm{GPa}$ \\
K2 & Pressure (EOS) constant & 0 \\
K3 & Pressure (EOS) constant & 0 \\
BULK & Bulking constant & 1.0 \\
D1 & Damage constant & 0.001 \\
D2 & Damage constant & 1.0 \\
\hline
\end{tabular}

however, during the course of ballistic impact, several different deformation and failure mechanisms involved, making the full penetration analysis of multilayer armor inevitable. Previous studies published on the penetration analysis of the armor systems are also noted to be limited to plates without an interlayer. The primary aim of the present work was to develop 3D finite elements models of armor systems with different interlayer materials in order to demonstrate the effect of interlayer material on the stress wave propagation in multilayer composite armor systems.

\section{Experimental}

The ballistic tests were carried out using $7.62 \times 51 \mathrm{~mm}$ M61 type AP projectiles in a ballistic laboratory. Ballistic tests were performed on the targets composed of alumina tiles bonded to a composite plate with and without an interlayer (Fig. 1a). The armor plate was composed of a hexagonal Alumina ceramic tile ('CoorsTek' AD-995), $101.6 \mathrm{~mm}$ wide and $14.1 \mathrm{~mm}$ thick and a 22 layers of plain weave S2-glass fabric (areal density $0.81 \mathrm{~kg} / \mathrm{m}^{2}$ ), having a [0/90] lay-up orientation (i.e. the fabric warp direction is at $0^{\circ}$ and the weft direction is at $90^{\circ}$ ), backing plate of $10.0 \mathrm{~mm}$ thick. EPDM rubber (Shore A 60), Teflon and aluminum foam were inserted between ceramic and composite layer. The thicknesses of EPDM rubber, Teflon and aluminum foam were sequentially 1.5, 2 and $18 \mathrm{~mm}$. The targets were initially mounted into a polyester resin in a rectangular glass mold. The thickness of polyester layer at the back surface of armor system was around $10 \mathrm{~mm}$ and each polyester-mounted target was bonded to a $20 \mathrm{~mm}$ thick steel plate with dimensions of $500 \times 500 \mathrm{~mm}^{2}$ and this steel plate was firmly clamped to the testing frame and adjusted to the desired point of impact. This secured a fixed boundary at the back surface of the target. All the multilayered armor plates were impacted at $0^{\circ}$ angle of attack with $7.62 \mathrm{~mm}$ AP NATO round using a gun mounted on a rigid mount with holding devices. The gun was properly aligned before each test. The velocities of impact were measured as $800 \pm 10 \mathrm{~m} / \mathrm{s}$. The projectile was fired from a distance of $15 \mathrm{~m}$. Four different configurations were tested; without an interlayer and with an interlayer of EPDM rubber, Teflon (Polarchip ${ }^{1}$ ) and aluminum metallic foam with a density of $0.438 \mathrm{~g} / \mathrm{cm}^{3}$. After the test the fracture pattern of the ceramic layer and the damage generated in the composite plate were investigated. During ballistic testing only partial penetration of the targets was observed. The tested armor plates were cut transversely using a low speed

\footnotetext{
${ }^{1}$ Polarchip $^{\mathrm{TM}}$ is a trademark of W.L. Gore, Inc.
} 
Table 3

Material properties of an S2-Glass/SC 15 epoxy composite [41].

\begin{tabular}{ll}
\hline Density, $\rho$ & $1.850 \mathrm{~g} / \mathrm{cm}^{3}$ \\
Elastic modulus, $\mathrm{E}_{\mathrm{A}}, \mathrm{E}_{\mathrm{B}}, \mathrm{E}_{\mathrm{C}}$ & $27.5,27.5,11.8 \mathrm{GPa}$ \\
Poisson's ratio, $\nu_{\mathrm{BA}}, \nu_{\mathrm{CA}}, \nu_{\mathrm{CB}}$ & $0.11,0.18,0.18$ \\
Shear modulus, $G_{\mathrm{AB}}, G_{\mathrm{BC}}, G_{\mathrm{CA}}$ & $2.9,2.14,2.14 \mathrm{GPa}$ \\
In-plane tensile strength, $S_{\mathrm{AT}}, S_{\mathrm{BT}}$ & $604 \mathrm{MPa}$ \\
In-plane compressive strength, $S_{\mathrm{AC}}, S_{\mathrm{BC}}$ & $291 \mathrm{MPa}$ \\
Out of plane tensile strength, $S_{\mathrm{CT}}$ & $58 \mathrm{MPa}$ \\
Fiber crush, $S_{\mathrm{FC}}$ & $850 \mathrm{MPa}$ \\
Fiber shear, $S_{\mathrm{FS}}$ & $300 \mathrm{MPa}$ \\
Matrix mode shear strength, $S_{\mathrm{AB}}, S_{\mathrm{BC}}, S_{\mathrm{CA}}$ & $75,58,58 \mathrm{MPa}$ \\
Residual compressive scale factor, SFFC & 0.3 \\
Friction angle, PHIC & 10 \\
Damage parameter, AM1, AM2, AM3, AM4 & $2.0,2.0,0.5,0.35$ \\
Delamination, S_DELM & 1.2 \\
Eroding strain, E_LIMIT & 0.2 \\
\hline
\end{tabular}

Table 4

Mechanical properties of EPDM rubber and Teflon [31].

\begin{tabular}{lllll}
\hline Material & $\begin{array}{l}\text { Modulus of } \\
\text { elasticity }(\mathrm{GPa})\end{array}$ & $\begin{array}{l}\text { Poisson's } \\
\text { ratio }\end{array}$ & $\begin{array}{l}\text { Density } \\
\left(\mathrm{kg} / \mathrm{m}^{3}\right)\end{array}$ & Other \\
\hline EPDM rubber & - & 0.4995 & 1200 & $\begin{array}{l}\mu_{1}=-4.684 \mathrm{MPa} \\
\mu_{2}=0.1954 \mathrm{MPa}\end{array}$ \\
& & & $\begin{array}{l}\alpha_{1}=-1.856, \alpha_{2}=2.992 \\
-\end{array}$ \\
\hline
\end{tabular}

diamond saw to avoid any further damage and analyzed microscopically.

\section{Modeling}

The numerical analysis to investigate the effect of interlayer material on the ballistic response of the multilayered armor was performed using the nonlinear finite element code LS-DYNA 971 [34]. In the damage analyses of the multilayered armor system, a full (no symmetry definitions) numerical model shown in Fig. 1b was used. A typical finite element model of a multilayered armor system consists of the normal impact of a $60^{\circ}$ conical-cylindrical projectile onto target. The projectile geometry was simplified in a shape, $7.62 \mathrm{~mm}$ in diameter and $28.1 \mathrm{~mm}$ in length. Its performance is similar to that of a $7.62 \mathrm{~mm}$ NATO armor-piercing (AP) round [35].

The constitutive response of the projectile was represented by Johnson-Cook fracture model [36]. In this model, the equivalent stress is expressed as:

$\sigma_{\mathrm{eq}}=\left(A+B \varepsilon_{\mathrm{eq}}^{n}\right)\left(1+\dot{\varepsilon}_{\mathrm{eq}}^{*}\right)^{\mathrm{C}}\left(1-T^{* m}\right)$

where $\varepsilon_{\text {eq }}$ is the equivalent plastic strain and $A, B, n, C$ and $m$ are the material constants. The dimensionless plastic strain rate is given by $\dot{\varepsilon}_{\text {eq }}^{*}=\dot{\varepsilon}_{\text {eq }} / \dot{\varepsilon}_{0}$, where $\dot{\varepsilon}_{0}$ a user defined reference strain rate. The homologous temperature is defined as $T^{*}=\left(T-T_{\mathrm{r}}\right) /\left(T_{\mathrm{m}}-T_{\mathrm{r}}\right)$, here $T$ is the absolute temperature, $T_{\mathrm{r}}$ is the room temperature and $T_{\mathrm{m}}$ is the melting temperature. A linear polynomial equation of state definition was used to simulate the behavior of the projectile. The material model constants for the projectile can be found in Ref. [34] and are further listed in Table 1.
The Johnson-Holmquist II (JH-2) [37] material model, a pressure- and strain-rate-sensitive material model developed for ballistic impact velocity range, was used to simulate damage evolution and dynamic failure of the ceramic layer. This material model includes a definition of the intact and fractured strength, a pressure-volume relationship that can include bulking, and a damage model that transitions the material from an intact state to a fractured state. The normalized equivalent stress for the strength is

$\sigma^{*}=\sigma_{\mathrm{i}}^{*}-D\left(\sigma_{\mathrm{i}}^{*}-\sigma_{\mathrm{f}}^{*}\right)$

where $\sigma_{i}^{*}$ is the normalized intact equivalent stress, $\sigma_{\mathrm{f}}^{*}$ is the normalized fracture stress and $D$ is the damage parameter varying between 0 and 1 . The normalized intact equivalent stress can be calculated from

$\sigma_{\mathrm{i}}^{*}=A\left(P^{*}+T^{*}\right)^{N}\left(1+C \ln \dot{\varepsilon}^{*}\right)$

and the normalized fracture stress is given as,

$\sigma_{\mathrm{f}}^{*}=B\left(P^{*}\right)^{M}\left(1+C \ln \dot{\varepsilon}^{*}\right) \leq$ SFMAX

where $\mathrm{P}^{*}, T^{*}$ and $\dot{\varepsilon}^{*}$ refer to normalized pressure, tension strength and strain rate, consecutively. They are normalized by the equivalent stress at the Hugoniot Elastic Limit (HEL). SFMAX is the maximum fracture strength. The damage from fracture is expressed as

$D=\sum \frac{\Delta \varepsilon^{\mathrm{P}}}{\varepsilon_{\mathrm{f}}^{\mathrm{P}}}$

where, $\Delta \varepsilon^{\mathrm{P}}$ is effective plastic strain during cycle of integration and $\Delta \varepsilon_{\mathrm{f}}^{\mathrm{P}}$ refers to the fracture plastic strain under a constant pressure. The plastic strain to fracture is given by

$\varepsilon_{\mathrm{f}}^{\mathrm{p}}=D_{1}\left(P^{*}+T^{*}\right)^{D_{2}}$

where $D_{1}$ and $D_{2}$ are damage constants. The material model constants of alumina ceramic used in the model were taken from Ref. [38] and are tabulated in Table 2.

Composite layer was modeled with MAT162 (MAT_COMPOSITE_DMG_MSC) material model [34,39]. MAT162 is based on the Hashin's failure criteria [40], which allows the user to monitor the initiation and progression of different failure modes such as tensile and compressive fiber failure, fiber crush, matrix failure and delamination. Element erosion is also incorporated into the material model. The material model parameters of S2 Glass/SC15 epoxy composite were taken from Ref. [41] and are tabulated in Table 3.

EPDM rubber was modeled with the Ogden material model [42]. In this model, the rubber is considered to be fully incompressible, since its bulk modulus greatly exceeds shear modulus. Rate effects are also taken into account through linear viscoelasticity. In this model, a hydrostatic work term is included in the strain energy functional. In the Ogden material model, the

Table 5

Mechanical properties of Aluminum foam [43].

\begin{tabular}{|c|c|c|c|c|c|c|}
\hline Material & $\begin{array}{l}\text { Modulus of uncompressed } \\
\text { material, } E_{\mathrm{u}}(\mathrm{GPa})\end{array}$ & $\begin{array}{l}\text { Density, } \\
\rho\left(\mathrm{kg} / \mathrm{m}^{3}\right)\end{array}$ & $\begin{array}{l}\text { Poisson's ratio of the } \\
\text { densified foam, } \nu_{\text {densified }}\end{array}$ & $\begin{array}{l}\text { Yield stress, } \\
\sigma_{\mathrm{y}}(\mathrm{MPa})\end{array}$ & $\begin{array}{l}\text { Volume fraction of } \\
\text { densified foam, } \nu_{\mathrm{f}}\end{array}$ & $\begin{array}{l}\text { Modulus of densified } \\
\text { foam, } E_{\mathrm{c}}(\mathrm{GPa})\end{array}$ \\
\hline Aluminum foam & 0.170 & 438 & 0.28 & 104 & 0.29 & 69 \\
\hline
\end{tabular}


Table 6

Mechanical properties of polyester.

\begin{tabular}{lllll}
\hline Material & $\begin{array}{l}\text { Modulus of } \\
\text { elasticity, } E(\mathrm{GPa})\end{array}$ & $\begin{array}{l}\text { Density, } \\
\rho\left(\mathrm{kg} / \mathrm{m}^{3}\right)\end{array}$ & $\begin{array}{l}\text { Poisson's } \\
\text { ratio }\end{array}$ & $\begin{array}{l}\text { Yield stress, } \\
\sigma_{\mathrm{y}}(\mathrm{MPa})\end{array}$ \\
\hline Polyester & 3.2 & 1133 & 0.35 & 113 \\
\hline
\end{tabular}

strain energy density can be expressed in terms of the principal stretches as,

$W\left(\lambda_{1}, \lambda_{2}, \lambda_{3}\right)=\sum_{P=1}^{N} \frac{\mu_{p}}{\alpha_{p}}\left(\lambda_{1}^{\alpha p}+\lambda_{2}^{\alpha p}+\lambda_{3}^{\alpha p}-3\right)$

where $N, \mu_{\mathrm{p}}$ and $\alpha_{\mathrm{p}}$ are the material constants. Under the assumption of incompressibility it can be expressed as

$W\left(\lambda_{1}, \lambda_{2}\right)=\sum_{P=1}^{N} \frac{\mu_{p}}{\alpha_{p}}\left(\lambda_{1}^{\alpha p}+\lambda_{2}^{\alpha p}+\lambda_{1}^{\alpha p} \cdot \lambda_{2}^{\alpha p}-3\right)$

Using this material model, the principal values of the Cauchy stresses can be computed as

$\sigma_{\alpha}=p+\lambda_{\alpha} \frac{\partial W}{\partial \lambda_{\alpha}}$
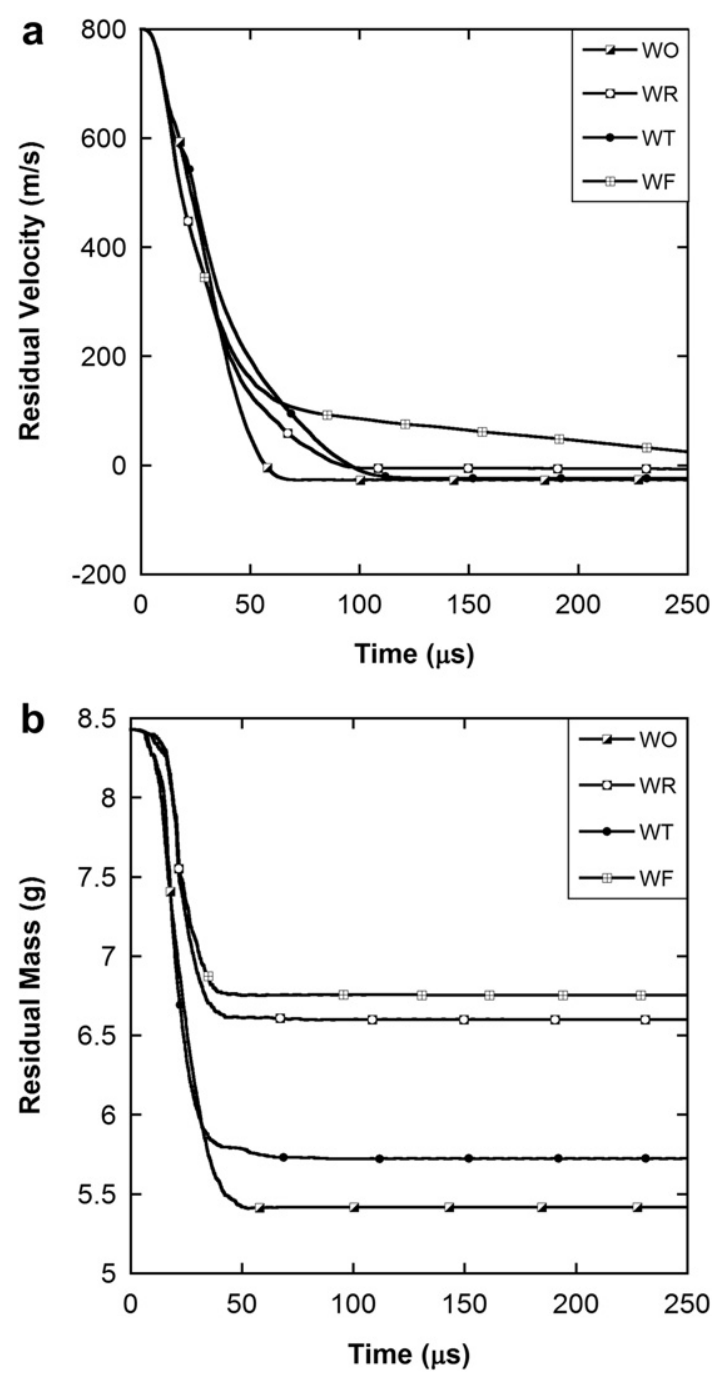

Fig. 2. Projectile (a) residual velocity and (b) residual mass versus time.
Teflon interlayer was modeled with the crushable foam model. This material model is dedicated to the modeling crushable foams with optional damping and tension cut-off. The unloading is fully elastic and tension is treated as elastic-perfectly plastic at the tension cut-off value. The material model constants of EPDM rubber and Teflon were taken from Ref. [31] and are tabulated in Table 4.

Aluminum foam was modeled with the MAT_HONEYCOMB material model $[34,39]$. This material model assumes the behavior as orthotropic before compaction and the stress tensors are uncoupled with zero Poisson's ratio. The normal and shear load displacement curves are defined as input. However, shear loaddisplacement curves are not always readily available and it can be assumed $\tau=\sigma / 2$. Previous studies showed that this is a reasonable assumption [26]. Shear and elastic moduli of the compacted foam varies linearly and constantly increases to those of the bulk materials with respect to relative volumes. The material model constants of Aluminum foam were taken from Ref. [43] and are tabulated in Table 5.

In Ogden and crushable foam and MAT_HONEYCOMB material models, the stress versus strain curves were used as input and the least squares fit to the experimental stress-strain curves were applied during the initialization phase.

Polyester mold in which the armor system was embedded was modeled with MAT24 (MAT_PIECEWISE_LINEAR_PLASTICITY) material model [34,39]. Again stress-strain curve was used as an input in this material model. The mechanical properties of the polyester used to mold armor system are listed in Table 6. Armor panel components and projectile were modeled with eight node solid elements with single integration point. The contact between the projectile and armor materials was modeled with CONTACT_ERODING_SURFACE_TO_SURFACE. The same contact definition was also used for the contact interfaces between the armor system constituents. The eroding contact options are needed when the elements forming one or both exterior surfaces experience failure during contact. Contact is also allowed to continue with the remaining interior elements. Erosion is modeled based on the criterion that elements do not contribute to the physics of penetration once their effective plastic strain hits a predefined critical value. Upon erosion, the interface between the components is redefined dynamically.

Mesh density has a significant effect on the results obtained. A standard mesh sensitivity analysis was carried out in order to

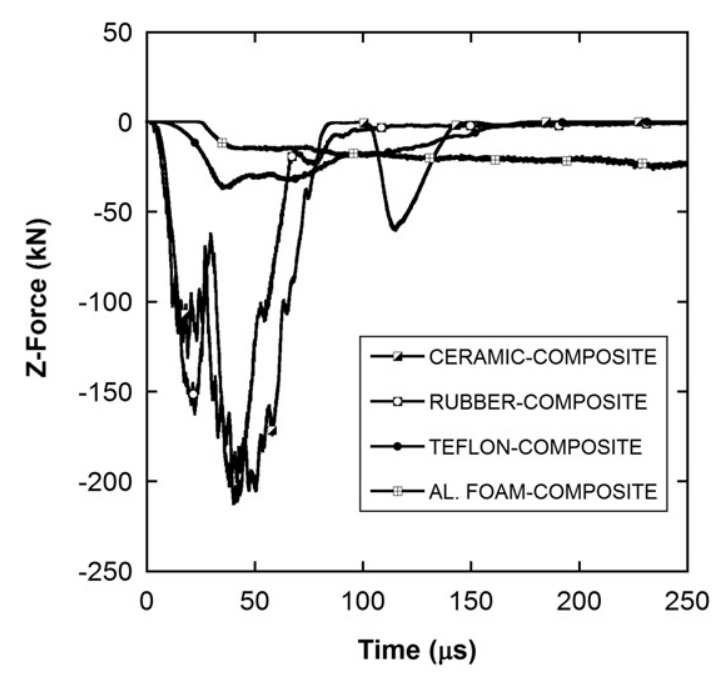

Fig. 3. The variation of the Z-force with time at the interlayer-composite interface. 
ensure that the results obtained were insensitive to the sizes of the elements used. The mesh sensitivity of the model was performed by varying the number of elements of the penetrator and the layers. The effect of mesh size on the penetration resistance force was studied for different mesh densities. The minimum
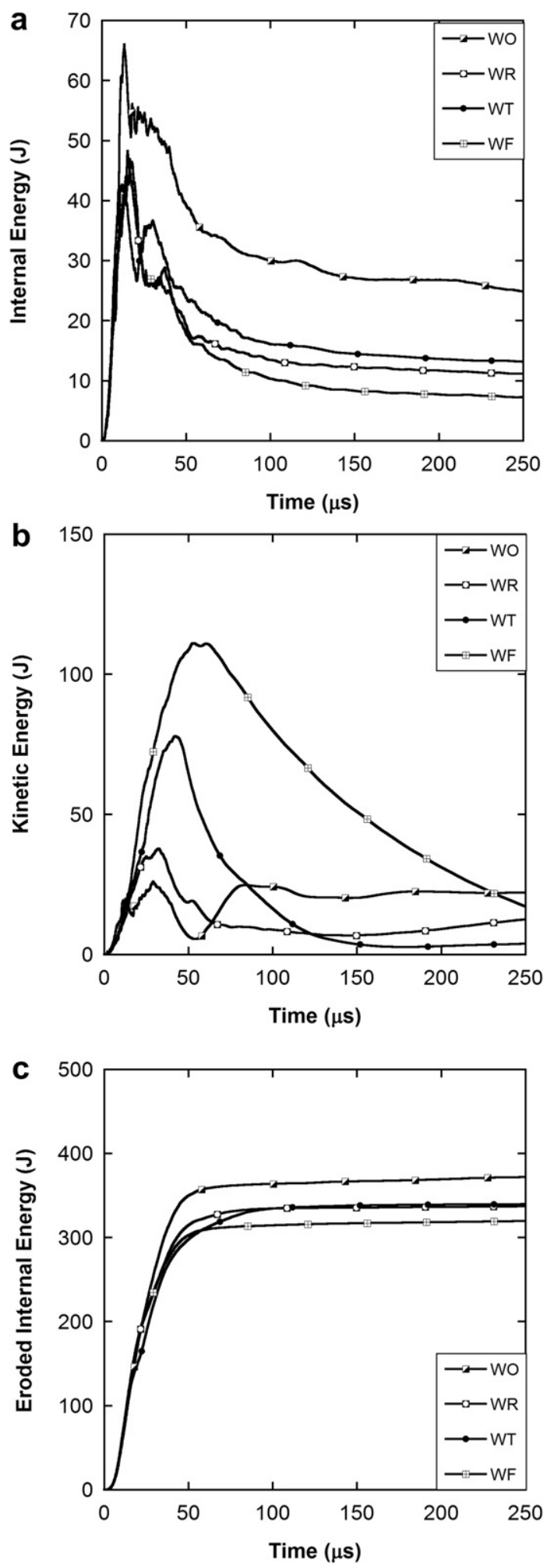

Fig. 4. The energy histories of the ceramic layer: (a) internal energy, (b) kinetic energy and (c) eroded internal energy. element size under the projectile was $0.5 \mathrm{~mm}$ in the present study. Throughout the text, the tested and modeled four different armor configurations were coded as; (a) without interlayer (baseline) (WO), (b) with rubber interlayer (WR), (c) with Teflon interlayer (WT) and (d) with aluminum foam interlayer (WF).

\section{Results and discussion}

The variation of the projectile residual velocity and projectile mass with time for the studied four different armor configurations are shown Fig. 2a and b, respectively. It is noted that the termination time $(250 \mu \mathrm{s})$ is long enough to allow the projectile come to a full stop and also short enough to prevent superfluous solution times. The projectile did not perforate the multilayer armor system for any of the configurations investigated numerically and experimentally. For the first $\sim 10 \mu \mathrm{s}$, the projectile slows down to $\sim 650 \mathrm{~m} / \mathrm{s}$ and the deceleration behavior is almost the same irrespective of the type of interlayer material used but, after that time slight deviations occur as seen in Fig. 2a. The projectile velocity in the configuration without interlayer decreases more steeply than those in with interlayer configurations, while the aluminum foam interlayer is the least effective in slowing the projectile velocity. In
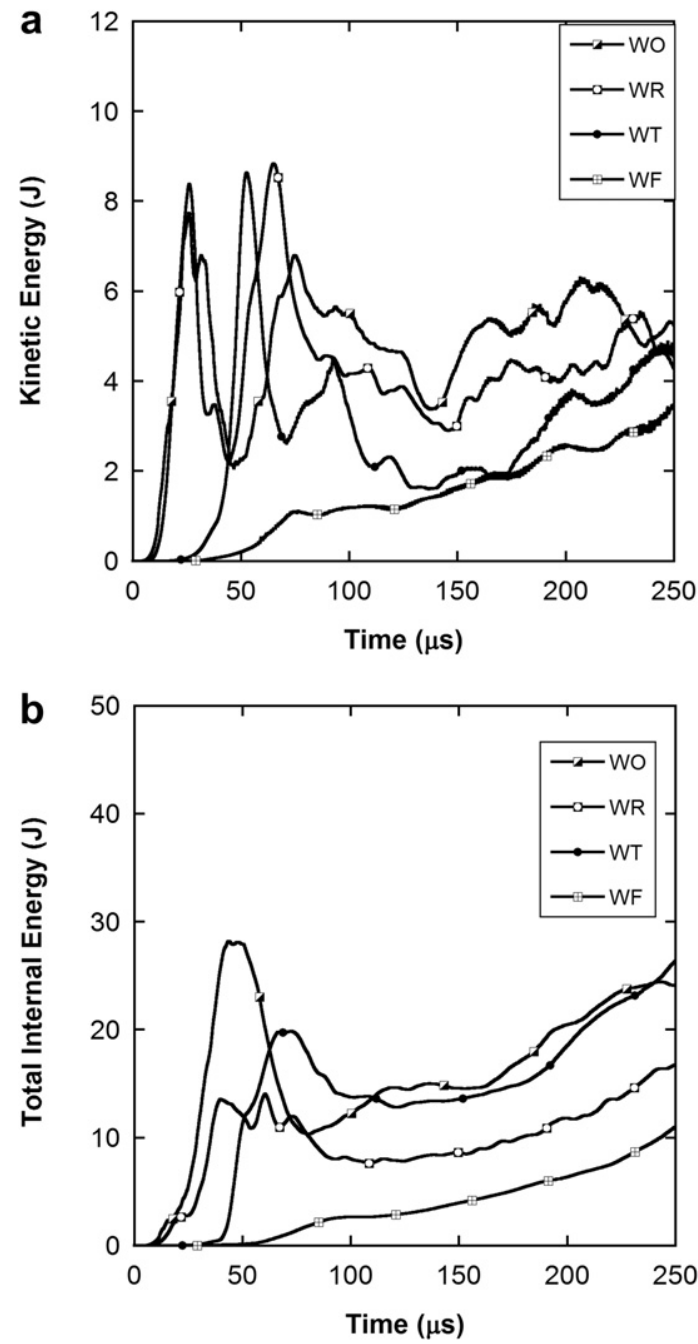

Fig. 5. The energy histories of the composite plate: (a) kinetic energy and (b) total internal energy. 


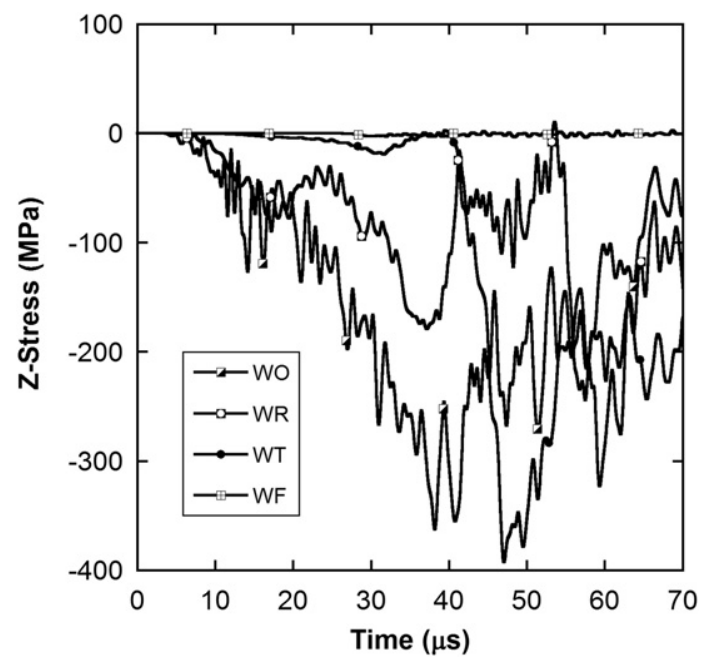

Fig. 6. Variations of the Z-stress component in the composite layer.

accord with this, the highest amount of projectile erosion occurs in the configuration without interlayer, while the aluminum foam interlayer leads to the lowest projectile erosion as seen in Fig. $2 \mathrm{~b}$. The analysis also showed that the configuration without interlayer exhibited the highest projectile eroded internal energy, which was in accord with the highest amount of projectile erosion in this configuration.

Fig. 3 depicts the distribution of the Z-force (the force in the projectile impact direction) at the interlayer-composite interface (between interlayer and composite layer). The presence of an interlayer between ceramic and composite layer as seen in Fig. 3 alters the stress wave transmission to the composite backing plate. It is noted in the same figure that the presence of rubber interlayer causes no delay in the initial force build-up in the composite for the first $\sim 35 \mu \mathrm{s}$, while it decreases the force values at the later stages of the impact as compared with the configuration without interlayer. Although the rubber interlayer has very low impedance initially, as the projectile penetrates into the ceramic layer its impedance rises rapidly. This is attributed to the constraining effect of surrounding material on the radial deformation of the interlayer in the vicinity of the projectile impact zone and the relatively high Poisson's ratio of the rubber. A similar behavior of EPDM rubber subjected to compressive stress wave loading was previously reported by Gama et al. [24,25]. It was shown that relatively low modulus rubber interlayer delayed the passage of the elastic stress wave into the composite and reduced the stress amplitude. It was also claimed that the damage in the composite layer was reduced in the presence of rubber interlayer. The behavior is quite different for Teflon and aluminum foam interlayer; the force values transmitted to the composite layer decreases significantly (Fig. 3). Teflon and aluminum foam interlayer also result in delays in the stress wave transmission to the composite backing plate. The axial modulus of the interlayer remains relatively low during the most of the deformation process for Teflon and aluminum foam interlayer configurations. Gama et al. [26] previously showed that aluminum foam interlayer in multilayered armor system behaved like a stress filter and effective stress wave transmission could only occur when the foam was completely densified.

The variations of the ceramic layer internal, kinetic and eroded internal energy with time are shown in Fig. $4 a-c$, respectively. As
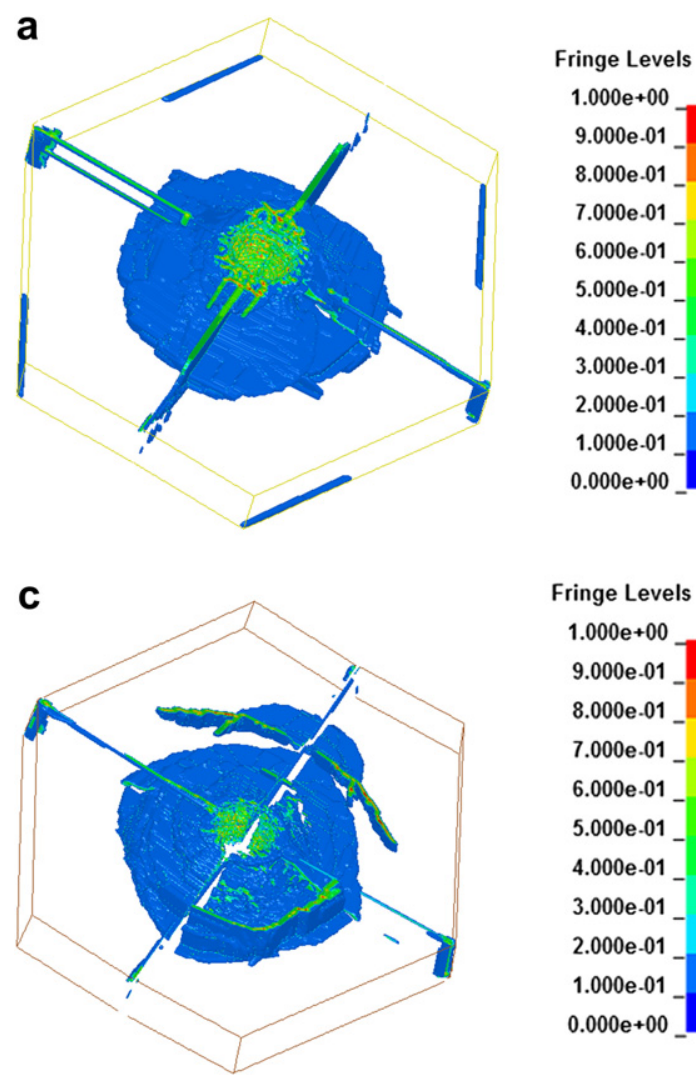

Fringe Levels

$1.000 \mathrm{e}+00$

$9.000 \mathrm{e}-01$

$8.000 \mathrm{e}-01$

7.000e-01

$6.000 \mathrm{e}-01$

5.000e-01

$4.000 \mathrm{e}-01$

$3.000 \mathrm{e}-01$

$2.000 \mathrm{e}-01$

$1.000 \mathrm{e}-01$

$0.000 e+00$
Fringe Levels

b
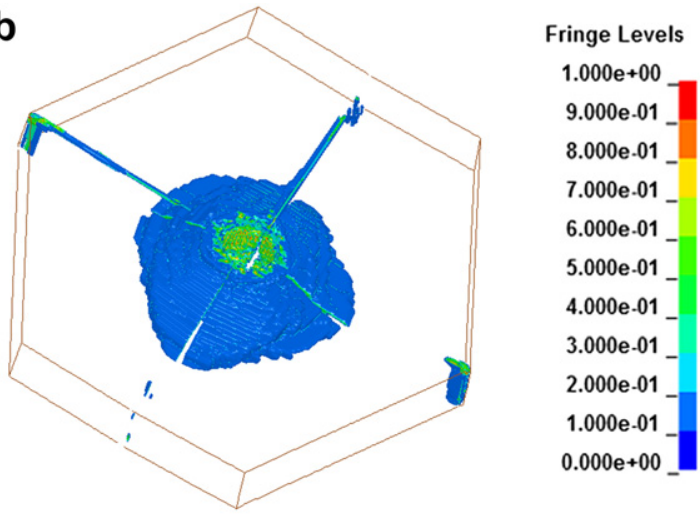

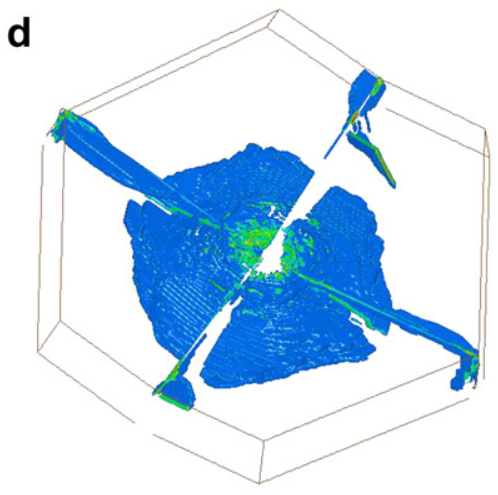

Fig. 7. Damage contours in the ceramic layer $250 \mu \mathrm{s}$ after impact: (a) without interlayer and (b) rubber, (c) Teflon and (d) aluminum foam interlayer configuration. 
the projectile penetration proceeds, the internal energy of the ceramic layer increases initially and then gradually decreases as seen in Fig. 4a. Without interlayer configuration ceramic layer shows highest energy values among all the configurations studied, while aluminum foam interlayer configuration shows the lowest. Correspondingly, the kinetic energy increases in about $50 \mu \mathrm{s}$, and then decreases (Fig. 4b). The kinetic energy imparted to the ceramic layer in Teflon and aluminum foam interlayer configurations is significantly higher than that of without interlayer and rubber interlayer configurations. This behavior is partly attributed to the relatively low axial modulus of the foam initially and during the projectile impact. The kinetic energy of the projectile is also dissipated as the projectile deforms and erodes, resulting in an increase in the eroding internal energy of the ceramic layer (Fig. 4c).

Fig. 5a and b shows the kinetic and total internal energy histories of the composite layer for the studied configurations. The simulations clearly indicate that the interlayer material has a strong effect on the energy transmitted to the composite layer during the projectile penetration. The similar kinetic energy increase in without interlayer and rubber interlayer configuration (Fig. 5a) confirms the increase of the rubber stiffness rapidly during penetration. Teflon and aluminum foam layers however cause significant delay in the energy histories (Fig. 5a, b). It is also noted in Fig. 5a, b that aluminum foam interlayer drastically reduces the amount of kinetic and total internal energies of the composite plate. The distributions of $\mathrm{Z}$ stress component for an element chosen in the composite layer at the mid-surface, which is located at the center of the composite plate, are shown as function of time in Fig. 6. As is seen in Fig. 6, the presence of the foam interlayer contributes to greatly reduced stress levels in the composite layer.

Fig. 7a-b shows the damage contours in the ceramic layer for without interlayer and with rubber, Teflon and aluminum foam interlayer configurations. As is seen in Fig. 7a, damage in ceramic layer is highly localized around the projectile impact zone. The rapidly stiffening rubber interlayer also causes damage to be localized around the projectile (Fig. 7b). Teflon and aluminum foam interlayer; on other hand, spread the damage zone in radial direction, significantly altering the damage formation in the ceramic layer (Fig. 7c, d). These results reveal that the interface material can have a strong effect on the fragmentation behavior of the ceramic layer and the subsequent damage formation, caused mainly by the reflection of the compressive waves at the ceramic-interlayer interface due to the acoustic impedance mismatch. The spreading of the damage zone is beneficial in reducing the stress transferred to the composite backing plate. A similar result was found previously by Zaera et al. [27] using different thicknesses and types of adhesives between ceramic front layer and metallic backing plate. The use of thicker layers of adhesive resulted in stress distribution over a wider area of the aluminum plate.

The magnitude and duration of reflected stress waves depend on the interlayer material and the thickness and the material properties of the interlayer as well as the adjacent layers. Rubber is a highly nonlinear material and its wave velocity is a function of stress-strain amplitude; therefore, the acoustic impedance and the transmission/reflection coefficients between adjacent layers are functions of the stress-strain amplitude. Relatively large pieces of the ceramic are observed around the impact axis in the rubber interlayer configuration (Fig. 8a), while the ceramic layers are observed to be efficiently fragmented in Teflon interlayer configuration (Fig. 8b). A similar efficient ceramic layer fragmentation was also seen for aluminum foam interlayer configuration. These observations are in agreement
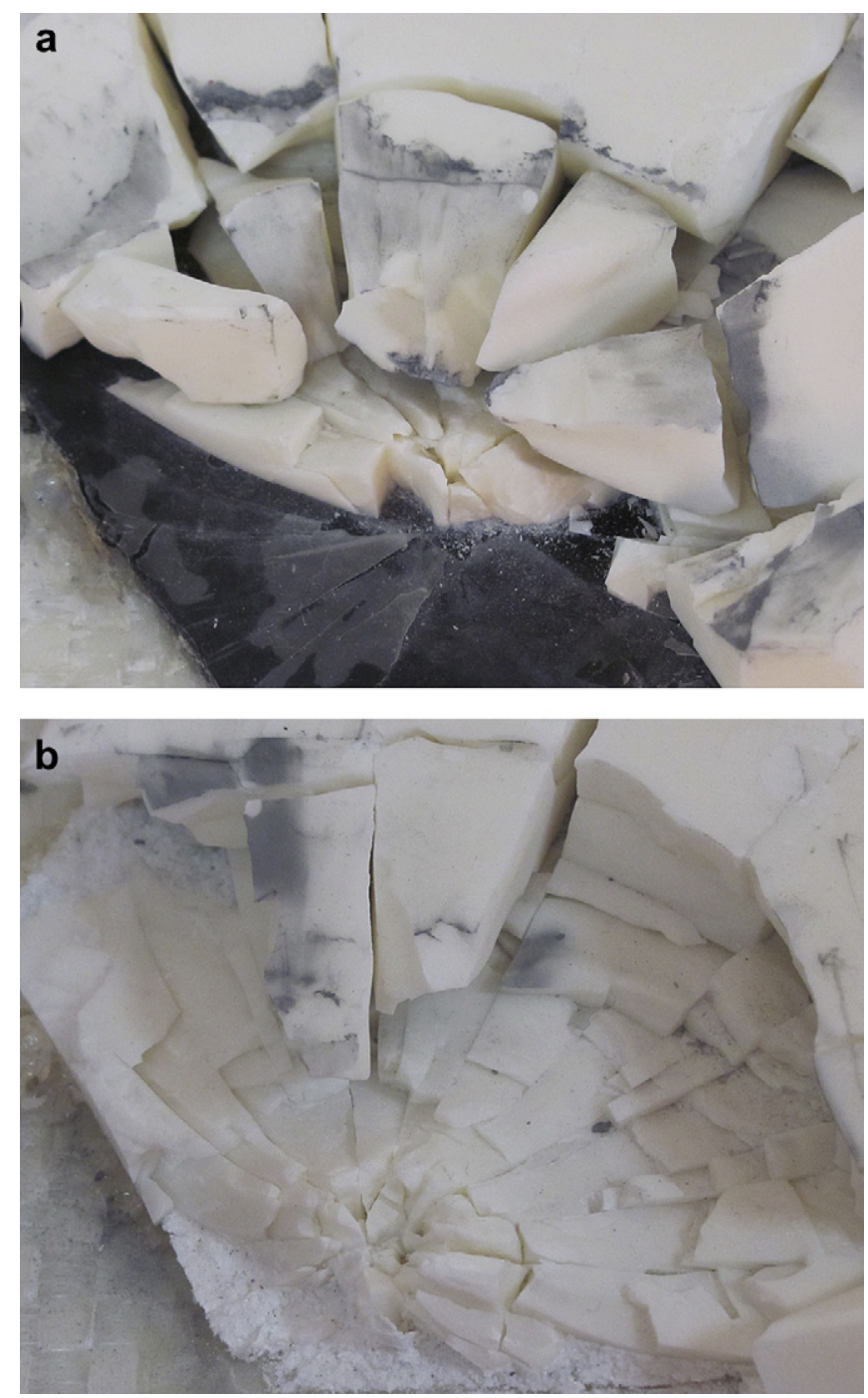

Fig. 8. The pictures of the ceramic layer after ballistic impact in (a) rubber and (b) Teflon interlayer configuration.

with the numerically determined damage counters in the ceramic layer.

Fig. 9a-d shows the delamination damage occurred during the ballistic impact in the composite layer in without interlayer and rubber, Teflon and aluminum foam interlayer configurations, respectively. The area of the damaged zone of the composite plate as depicted in these figures is localized around the top outermost layers. The delamination damage in the composite layer is relatively narrower in Teflon and aluminum foam interlayer configuration (Fig. 9c, d) than that in without and rubber interlayer configuration (Fig. 9a, d). In aluminum foam interlayer configuration, the area of delamination damage is noted to be significantly reduced (Fig. 9d). The present results clearly show that interlayer material have significant effect on the ballistic performance of the composite armor. As the extent of the delamination damage of the composite layer and fragmentation of the ceramic layer depend on the thickness of the interlayer material, the present results are only valid for the investigated interlayer material thicknesses. The effect of interlayer material thicknesses on the ceramic front layer and composite backing plate damage will be investigated in another study. 

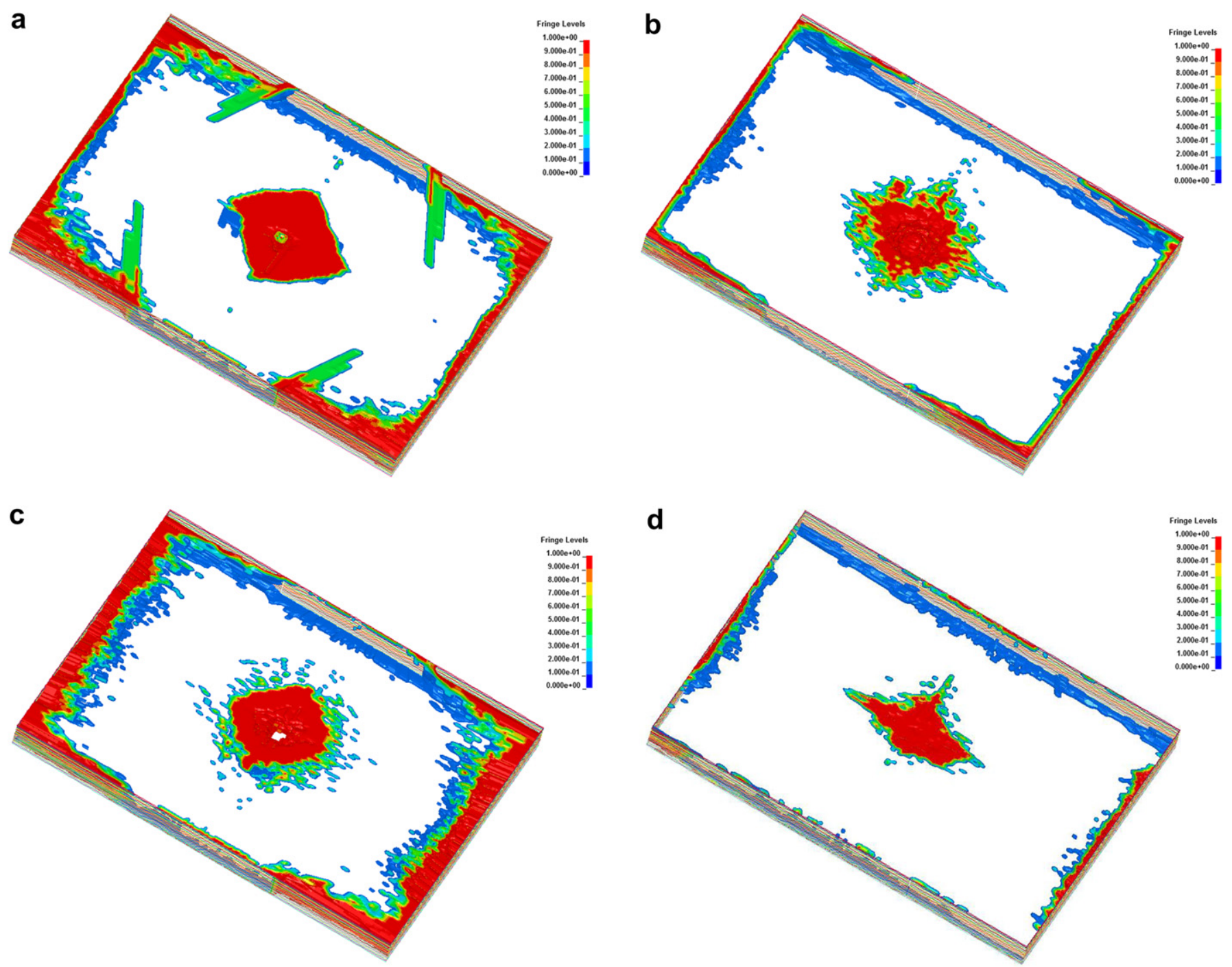

Fig. 9. Delamination damage contours in the composite layer $250 \mu$ s after impact: (a) without interlayer and (b) rubber, (c) Teflon and (d) aluminum foam interlayer configuration.

\section{Conclusions}

The effect of the interlayer material on the ballistic performance of composite armor was investigated both experimentally and numerically. The presence of interlayer altered the stress wave transmission between the layers. Although, rubber interlayer did not cause any significant delay in the initial stress build-up in the composite layer, Teflon and aluminum foam interlayer caused a significant delay and reduction in the magnitude of the stress transmitted to the composite backing plate. In addition, Teflon and aluminum foam interlayer configurations imparted higher kinetic energy to the ceramic layer than without interlayer and rubber interlayer configuration. Damage in the ceramic layer was highly localized around the projectile impact zone for without interlayer and rubber interlayer configuration, while aluminum foam and Teflon interlayer spread the damage zone in the radial direction. Relatively large pieces of the ceramic around the impact axis in the rubber interlayer configuration were observed while the ceramic layer was efficiently fragmented in aluminum foam and Teflon interlayer configuration.

\section{Acknowledgement}

The authors would like to thank the Scientific and Technical Council of Turkey (TUBITAK) for the grant \# 106M353. The authors thank W.L. Gore \& Associates Inc. for provision of the Teflon (Polarchip $^{\mathrm{TM}}$ ) interlayers and Dr. Ian W. Hall for supplying ceramic/ composite layers.

\section{References}

[1] Borvik T, Langseth M, Hopperstad OS, Malo KA. Ballistic penetration of steel plates. Int J Impact Eng 1999;22:855-85.

[2] Gupta NK, Madhu V. Normal and oblique impact of a kinetic-energy projectile on mild-steel plates. Int J Impact Eng 1992;12:333-43.

[3] Littlefield DL, Anderson CE, Partom Y, Bless SJ. The penetration of steel targets finite in radial extent. Int J Impact Eng 1997;19:49-62.

[4] Sorensen BR, Kimsey KD, Silsby GF, Scheffler DR, Sherrick TM, Derosset WS. High-velocity penetration of steel targets. Int J Impact Eng 1991;11:107-19.

[5] Anderson CE, Morris BL. The Ballistic performance of confined $\mathrm{Al}_{2} \mathrm{O}_{3}$ ceramic tiles. Int J Impact Eng 1992;12:167-87.

[6] Anderson CE, Mullin SA, Piekutowski AJ, Blaylock NW, Poormon KL. Scale model experiments with ceramic laminate targets. Int J Impact Eng 1996;18: $1-22$.

[7] Chou SC, DeLuca E, Prifti J, Betheney W. Ballistic impact damage of S 2-glassreinforced plastic structural armor. Compos Sci Technol 1998;58:1453-61.

[8] Collombet F, Lalbin X, Lataillade JL. Impact behavior of laminated composites: physical basis for finite element analysis. Compos Sci Technol 1998;58: 463-78.

[9] Davies GAO, Zhang X. Impact damage prediction in carbon composite structures. Int J Impact Eng 1995;16:149-70.

[10] Kumar KS, Bhat TB. Response of composite laminates on impact of high velocity projectiles. Key Eng Mat 1998;141-1:337-48. 
[11] Shokrieh MM, Javadpour GH. Penetration analysis of a projectile in ceramic composite armor. Compos Struct 2008;82:269-76.

[12] Vaidya UK, Deka LJ, Bartus SD. Damage evolution and energy absorption of Eglass/polypropylene laminates subjected to ballistic impact. J Mater Sci 2008; 43:4399-410.

[13] Yadav S, Ravichandran G. Penetration resistance of laminated ceramic/polymer structures. Int J Impact Eng 2003;28:557-74.

[14] Gooch WA, Chen BHC, Burkins MS, Palicka R, Rubin J, Ravichandran R. Development and ballistic testing of a functionally gradient ceramic/metal applique. Mater Sci Forum 1999;308-311:614-21.

[15] Liu LS, Zhang QJ, Zhai PC, Zhu CC. Impact characteristic analysis of ceramic/ metal FGM. Mater Sci Forum 2003;423-4:641-4.

[16] Navarro C, Lopez-Puente J, Arias A, Zaera R. The effect of the thickness of the adhesive layer on the ballistic limit of ceramic/metal armours. An experimental and numerical study. Int J Impact Eng 2005;32:321-36.

[17] Sadanandan S, Hetherington JG. Characterisation of ceramic/steel and ceramic/aluminium armours subjected to oblique impact. Int J Impact Eng 1997;19:811-9.

[18] Sun CT, Roeder BA. Dynamic penetration of alumina/aluminum laminates: experiments and modeling. Int J Impact Eng 2001;25:169-85.

[19] Zhang ZG, Wang MC, Song SC, Li M, Sun ZJ. Influence of panel/back thickness on impact damage behavior of alumina/aluminum armors. J Eur Ceram Soc 2010;30:875-87.

[20] Abrate S. Wave propagation in lightweight composite armor. J Phys IV 2003; 110:657-62.

[21] Bruck HA. A one-dimensional model for designing functionally graded materials to manage stress waves. Int J Solids Struct 2000;37:6383-95.

[22] Gama BA, Bogetti TA, Fink BK, Mahfuz H, Gillespie JW. Study of throughthickness wave propagation in multi-layer hybrid lightweight armor. 13th Annual technical conference of the American Society for Composites, Baltimore, MD; 1998

[23] Mines RAW. A one-dimensional stress wave analysis of a lightweight composite armour. Compos Struct 2004;64:55-62.

[24] Gama BA, Gillespie JW, Bogetti TA, Fink B. Innovative design and ballistic performance of lightweight composite integral armor. SAE 2001 World Congress, Detroit, MI; 2001.

[25] Gama BA, Gillespie JW, Mahfuz H, Bogetti TA, Fink B. Effect of non-linear material behavior on the through-thickness stress wave propagation in multi-layer hybrid lightweight armor. Adv Comput Eng Sci Technol Sci Press; 2000:157-62.

[26] Gama BA, Bogetti TA, Fink BK, Yu CJ, Claar TD, Eifert HH, et al. Aluminum foam integral armor: a new dimension in armor design. Compos Struct 2001;52: 381-95.
[27] Zaera R, Sanchez-Saez S, Perez-Castellanos JL, Navarro C. Modelling of the adhesive layer in mixed ceramic/metal armours subjected to impact. Compos Part A-Appl S 2000;31:823-33.

[28] Zaera R, SanchezGalvez V. Modelling of fracture processes in the ballistic impact on ceramic armours. J Phys IV 1997;7:687-92.

[29] Ding JL, Robbins JR, Gupta YM. Load spreading and penetration resistance of layered structures - a numerical study. Int J Impact Eng 2004;30: 593-615.

[30] Gupta YM, Ding JL. Impact load spreading in layered materials and structures: concept and quantitative measure. Int J Impact Eng 2002;27:277-91.

[31] Tasdemirci A, Hall IW. Experimental and modeling studies of stress wave propagation in multilayer composite materials: low modulus interlayer effects. J Compos Mater 2005;39:981-1005.

[32] Tasdemirci A, Hall IW. The effects of plastic deformation on stress wave propagation in multi-layer materials. Int J Impact Eng 2007;34:1797-813.

[33] Tasdemirci A, Hall IW. Numerical and experimental studies of damage generation in multi-layer composite materials at high strain rates. Int J Impact Eng 2007;34:189-204.

[34] Teland JA. Numerical simulation of light armour piercing ammunition against steel. Norway: Norwegian Defence Research Establishment; 2005. FFI/ RAPPORT-2005/00126.

[35] Fawaz Z, Zheng W, Behdinan K. Numerical simulation of normal and oblique ballistic impact on ceramic composite armours. Compos Struct 2004;63: 387-95.

[36] Johnson GR, Cook WH. Fracture characteristics of three metals subjected to various strains, strain rates, temperatures and pressures. Eng Fract Mech 1985;21:31-48.

[37] Johnson GR, Holmquist TJ. An improved computational constitutive model for brittle materials. High-Pressure Sci Technol 1994;1993(Pts. 1 and 2):981-4.

[38] Krashanitsa R, Shkarayev S. Computational study of dynamic response and flow behavior of damaged ceramics. 46th AIAA/ASME/ASCE/AHS/ASC structural dynamics \& materials conference, Austin, Texas; 2005, p. 1-8.

[39] LSTC. LS-DYNA theoretical user's manual. Livermore, CA: Livermore Software Technology Corporation; 2006.

[40] Hashin Z. Failure criteria for unidirectional fiber composites. J Appl Mech-T ASME 1980;47:329-34.

[41] Xiao JR, Gama BA, Gillespie JW. Progressive damage and delamination in plain weave S-2 glass/SC-15 composites under quasi-static punch-shear loading. Compos Struct 2007;78:182-96.

[42] Ogden RW. Non-linear elastic deformations. New York: Halsted Press; 1984.

[43] Ergonenc C. Development and design of closed-cell alumium foam-based lightweight sandwich structures for blast protection. M.Sc. thesis, Izmir Institute of Technology, Turkey; 2008. 